\title{
PERANCANGAN FLYBACK CONVERTER UNTUK CATU DAYA DRIVER MOTOR BLDC ( BRUSHLESS DIRECT CURRENT )
}

\author{
Agus Mahendra ${ }^{1}$, Sapril $^{2}$, Maryantho Masarrang ${ }^{3}$ \\ ${ }^{1,2)}$ Mahasiswa, Fakultas Teknik, Jurusan Teknik Elektro, Universitas Tadulako \\ E-mail : hendra.pawisian@gmail.com \\ ${ }^{3)}$ Dosen, Fakultas Teknik, Jurusan Teknik Elektro, Universitas Tadulako
}

\begin{abstract}
Flyback Converter is an electronic circuit that can increase the output voltage value, the voltage value can be adjusted by changing the value of the duty cycle. This Flyback Converter will be controlled by the Pulse Width Modulation method as the output voltage setting and this research is equipped with a feedback function as monitoring and control of Input Pulse Width Modulation.

This designed flyback converter aims to provide an isolated power supply as a power source for Brushless Direct Current Motor drivers, and this research was conducted to analyze how much power the flyback converter can produce to be able to supply Brushless Direct Current Motor drivers.

The results of the analysis obtained in the research Design of flyback converter for power supply of BLDC (Brushless Direct Current) motor driver that is flyback converter is given an input voltage of $31 \mathrm{VDC}$ and output voltage of $15 \mathrm{VDC}$, rheostat load with a capacity of $39 \mathrm{Ohm}$, a frequency of $31 \mathrm{KHz}$ in the form of a box wave duty cycle reaches $70 \%$. Flyback converter designed to produce maximum power of 49.6 watts on $70 \%$ duty cycle testing.
\end{abstract}

Keywords: Pulse Width Modulation, BLDC motor driver, flyback converter, duty cycle

\section{I . Pendahuluan}

Perkembangan teknologi transportasi di indonesia mengalami kemajuan yang sangat pesat. Semakin meningkatnya jumlah kendaraan mengakibatkan komsumsi bahan

bakar minyak (BBM) meningkat. Hal ini memicu pengembangan penggunaan energi listrik pada sistem transportasi sebagai pengganti BBM, yaitu dengan produksi mobil listrik. Mobil listrik adalah mobil yang penggerak utamanya berupa motor listrik yang sumbernya berasal dari energi listrik yang tersimpan di dalam baterai.

Kebutuhan energi listrik merupakan hal yang sangat penting untuk menunjang teknologi saat ini khususnya perkembangan mobil listrik, masih banyak masalah dalam mendesain sistem kontrol dari mobil listrik, salah satunya pada catu daya DC untuk driver kontrol, sehingga dibutuhkan rangkaian catu daya yang dapat dikendalikan oleh ground yang terpisah guna untuk menghindari pengaruh Electro Magnetic Interference (EMI). Efek dari EMI dapat menganggu, menghambat, merusak atau membatasi kinerja dari perangkat elektronik dan peralatan listrik.

Sistem penyedia daya tegangan searah (DC), yang dihasilkan melalui konversi tegangan dc, masukan ke bentuk tegangan dc dan keluaran yang lebih tinggi atau lebih rendah. Konversi tegangan DC ini sering disebut sebagai DC-DC konverter. Tegangan DC dapat dihasilkan oleh baterai yang akan menaikkan tegangan/arus (DC) menggunakan Flyback Converter. Flyback Converter adalah suatu rangkaian elektronika yang dapat menaikkan nilai tegangan keluaran, nilai tegangan tersebut 
dapat diatur dengan mengubah nilai duty cycle. [1]

Oleh karna itu penulis mengambil judul penelitian tugas akhir "PERANCANGAN FLYBACK CONVERTER UNTUK CATU DAYA DRIVER MOTOR BLDC (Brushless Direct Current)".

\subsection{Mikrokontroler Arduino Nano}

Arduino Nano adalah salah satu varian dari produk board mikrokontroller keluaran Arduino. Arduino Nano adalah board Arduino terkecil, menggunakan mikrokontroller Atmega 328 untuk Arduino Nano 3.x dan Atmega168 untuk Arduino Nano 2.x. Varian ini mempunyai rangkaian yang sama dengan jenis Arduino Duemilanove, tetapi dengan ukuran dan desain PCB yang berbeda. Arduino Nano tidak dilengkapi dengan soket catu daya, tetapi terdapat pin untuk catu daya luar atau dapat menggunakan catu daya dari mini USB port. Arduino Nano didesain dan diproduksi oleh Gravitech. Arduino dapat dikoneksikan dengan komputer menggunakan kabel USB [2].

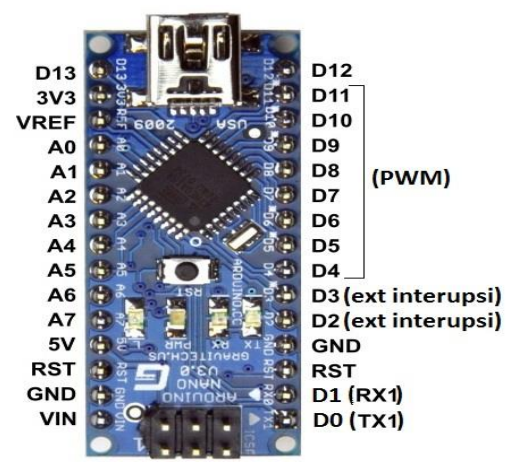

Gambar 1. Board arduino uno

Arduino memiliki kelebihan tersendiri dibanding board mikrokontroler yang lain, selain bersifat open source, Arduino juga mempunyai bahasa pemrogramannya sendiri yang berupa bahasa C. selain itu dalam board Arduino sendiri sudah terdapat loader yang berupa USB sehingga memudahkan pengguna ketika memprogram mikrokontroler di dalam Arduino.

\subsection{Mosfet}

Mosfet (Metal oxide FET) memiliki drain, source dan gate. Namun perbedaannya gate terisolasi oleh suatu bahan oksida. Gate sendiri terbuat dari bahan metal seperti aluminium. Oleh karena itulah transistor ini dinamakan metal-oxide. Karena gate yang terisolasi, sering jenis transistor ini disebut juga IGFET yaitu insulated-gate FET. [3].

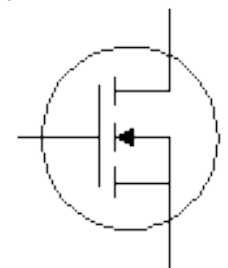

(a)

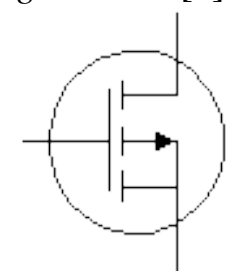

(b)
Gambar 2. Simbol MOSFET,

(a) kanal-n, (b) kanal-p

\subsection{Flyback Converter}

Flyback converter adalah converter yang bekerja berdasarkan cara kerja buckboostkonverter yang membedakan antara keduanya adalah flyback converter memiliki tranformator frekuensi tinggi yang berfungsi sebagai induktor dan juga sebagai isolasi magnetis antara input dan output. [4].

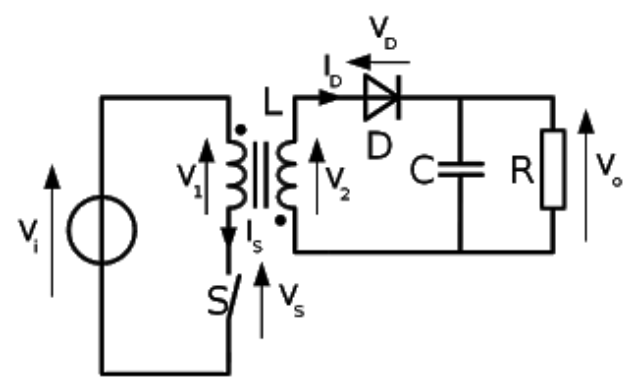

Gambar 3. Rangkaian Flyback Converter

\subsection{Motor BLDC}

Motor BLDC atau dapat disebut juga motor BLAC adalah motor listrik synchronous AC 3 fasa. Perbedaan pemberi nama ini terjadi karena BLDC memiliki BEMF berbentuk trapezoid sedangkan BLAC memiliki BEMF berbentuk sinosuidal. [5]. 

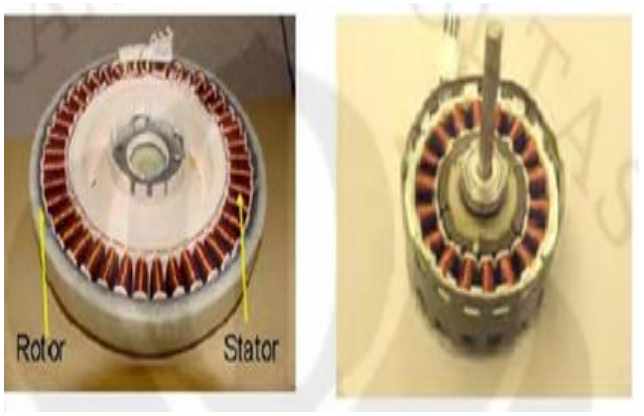

Gambar 4. Penampangan Motor BLDC

Secara umum motor BLDC terdiri dari dua bagian, yakni, rotor, bagian yang bergerak yang terbuat dari permanen magnet dan stator, bagian yang tidak bergerak yang terbuat dari kumparan 3 fasa. Walaupun merupakan motor listrik synchronous AC 3 fasa, motor ini tetap disebut dengan BLDC karena pada implementasinya BLDC menggunakan sumber DC sebagai sumber energi utama yang kemudian diubah menjadi tegangan $\mathrm{AC}$ dengan menggunakan inverter 3 fasa. Tujuan dari pemberian tegangan AC 3 fasa pada stator BLDC adalah menciptakan medan magnet putar stator untuk menarik magnet rotor.

\subsection{PWM ( Pulse Width Modulation )}

PWM merupakan sebuah mekanisme untuk membangkitkan sinyal keluaran yang periodenya berulang antara high dan low dimana kita dapat mengontrol durasi sinyal high dan low sesuai dengan yang kita inginkan. Duty cycle merupakan presentase periode sinyal high dan periode sinyal low, presentase duty cycle akan bebanding lurus dengan tegangan rata-rata yang dihasilkan. Modulasi lebar pulsa Pulse Width Modulation yang terlihat pada gambar 2 . dicapai / diperoleh dengan bantuan sebuah gelombang kotak,dimana siklus kerja (duty cycle) gelombang dapat diubah-ubah untuk mendapatkan sebuah tegangan keluaran yang bervariasi yang merupakan nilai ratarata dari gelombang tersebut. [5].

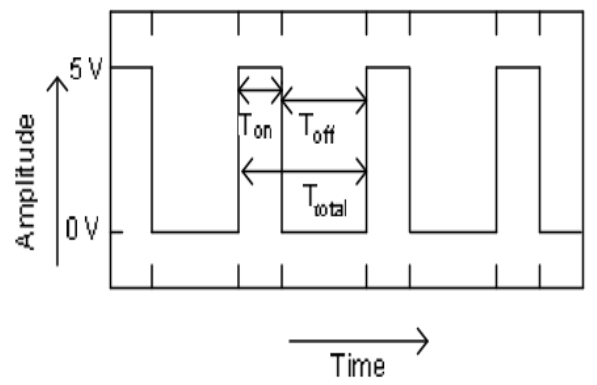

Gambar 5. Bentuk gelombang kotak (pulsa) dengan kondisi high 5 Volt dan low 0 Volt

\section{Metode Penelitian}

\subsection{Bahan dan Alat Penelitian}

Adapun bahan dan alat dan digunakan

dalam penelitian mengenai alat monitoring suhu, kelembaban dan level air pada rumah walet berbasis arduino uno ini antara lain sebagai berikut :

\subsubsection{Bahan Penelitian}

Berikut adalah bahan-bahan yang digunakan dalam penelitian ini Perangkat keras (Hardware) Pertama Komponen elektronika antara lain : Mikrokontroler Arduino Nano, Rangkaian Flyback Converter, Rangkaian Arduino Nano, Power Supply, IC 7812 dan IC 7815, Transformator, Kabel. Kedua Perngkat lunak yaitu: Arduino 1.5.8, Diptrace 2.4, Proteus Professional.v7.0.

\subsubsection{Alat Penelitian}

Berikut adalah alat-alat yang digunakan Dalam penelitian ini: Laptop dengan spesifikasi : Processor Intel Core i5 inside, Memory 8 Giga RAM, Solder, Multimeter,LCR meter, Osiloscope, Bor Listrik, Gurinda dan Toolset.

\subsection{Cara Penelitian}

Jenis penelitian yang penulis gunakan dalam penelitian ini adalah dengan metode kualitatif berbasis eksperimen dimana penulis membuat sebuah perancangan flyback converter untuk catu daya driver motor BLDC setelah itu penulis melakukan 
percobaan, pengujian dan pengambilan data - data yang diperlukan dalam penelitian ini. Adapun cara penelitian ini dapat dijabarkan sebagai berikut :

\subsubsection{Studi Kepustakaan}

Pada tahap studi kepustakaan merupakan langkah dimana peneliti mencari permasalahan yang didapatkan pada penelitian sebelumnya mengenai perancangan Flyback Converter dan pada penelitian ini akan dilakukan pengembangan dari kekurangan yang dihadapi penelitian-penelitian sebelumnya. Adapun jurnal-jurnal yang berkaitan dengan penelitian ini akan dikumpul lalu dijadikan materi - materi pendukung.

\subsubsection{Perancangan Alat}

\subsubsection{Blok Diagram perancangan alat}

Prinsip kerja dari sistem yang digambarkan dalam bentuk diagram blok tersebut dimana mikrokontroler mengambil peran penting sebagai pusat kontrol sistem ini. Diawal memberikan catu daya sebesar $31 \mathrm{~V}$ maka tegangan output modul dalam keadaan $0 \mathrm{~V}$, untuk mengatur output dapat mengatur nilai duty Cycle pada output control yang terhubung pada PWM arduino nano. Nilai duty Cycle ini sangat menentukan output atau kondisi modul flyback, pengaturan duty Cycle menggunakan pengaturan putar yaitu potensiometer. Pengaturan menggunakan potensiometer dapat menentukan keluaran $0-15 \mathrm{~V}$.

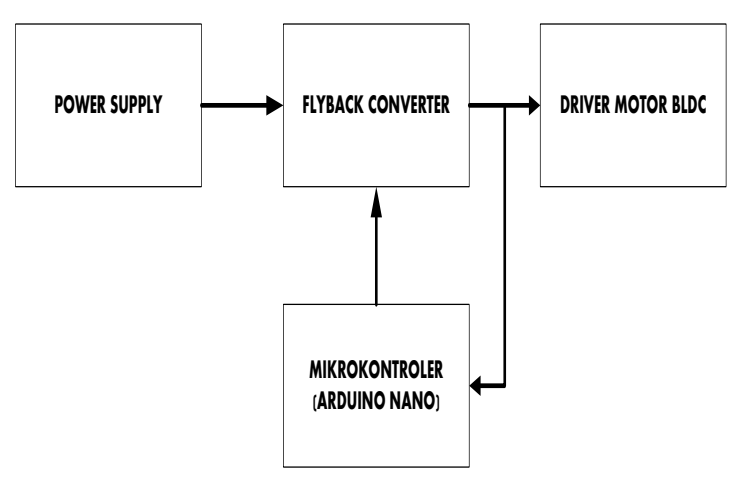

Gambar 6. diagram blok Perancangn flyback converter

\subsubsection{Perancangan Perangkat keras}

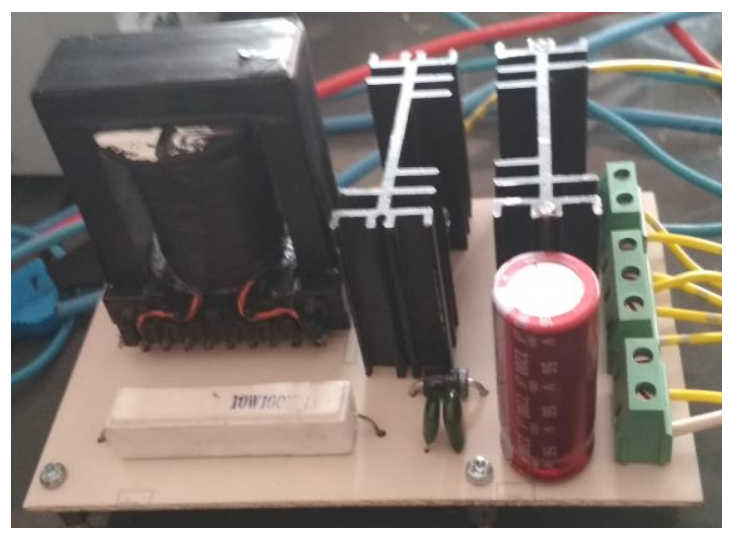

Gambar 7. Rancangan Flyback Converter

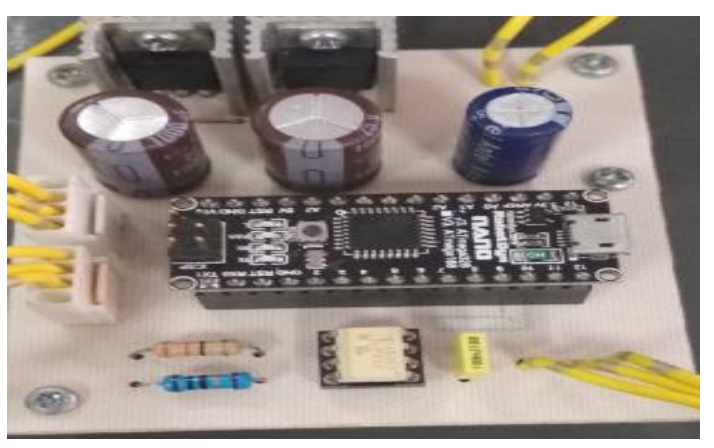

Gambar 8. Rancangan Microkontroller

\subsubsection{Perancangan Flowchart}

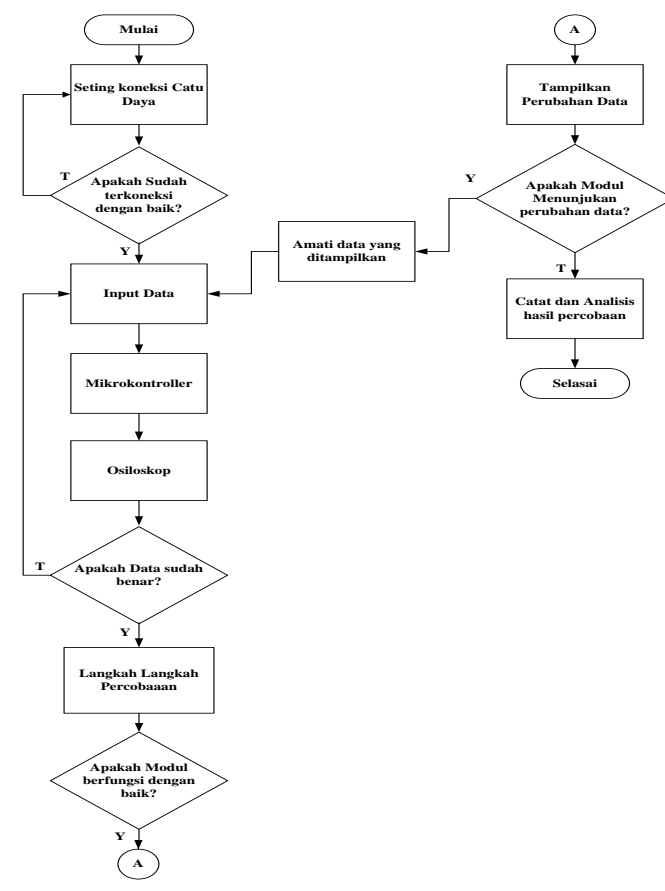

Gambar 9. Diagram Alir Penelitian 


\section{Hasil dan Pembahasan}

\subsection{Modul Flyback Converter}

Gambar 10. merupakan perangkat flyback converter yang diperoleh pada hasil penelitian " Perancangan Flyback Converter Untuk Catu Daya Driver Motor BLDC (Brushless Direct Current) ", dengan hasil data pengujian sebagai berikut

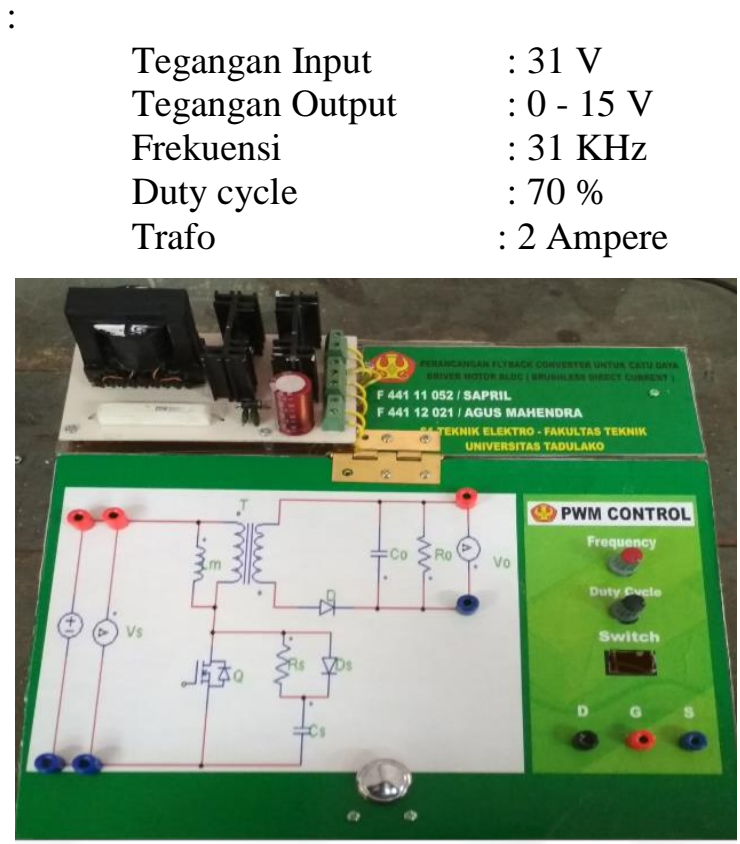

Gambar 10. Modul Flyback Converter

Trafo yang digunakan diambil dari bekas tv 24 inchi, kemudian dilakukan penggulungan kembali menggunaakan kawat $0,3 \mathrm{~mm}$ dengan tegangan yang mampu disupply maksimum $31 \mathrm{~V}$. Untuk daya yang disediakan dapat diketahui dengan persamaan sebagai berikut :

$$
P=V . I
$$

Dimana :

$$
\begin{aligned}
& \mathrm{V}=\text { Tegangan yang dihasilkan } \\
& \text { (Volt) } \\
& \mathrm{I}=\text { Besar Arus (Ampere) } \\
& \mathrm{P}=\text { Daya (Watt) }
\end{aligned}
$$

\begin{tabular}{|c|c|c|c|c|c|c|c|c|}
\hline \multirow[b]{2}{*}{ No. } & \multirow[b]{2}{*}{$\begin{array}{l}\text { Duty } \\
\text { Cycle }\end{array}$} & \multirow{2}{*}{$\begin{array}{c}\text { Beb } \\
\text { an } \\
(\Omega)\end{array}$} & \multicolumn{4}{|c|}{ Hasil pengujian } & \multicolumn{2}{|c|}{ Hasil perhitungan } \\
\hline & & & $\begin{array}{l}\text { Vin } \\
\text { (V) }\end{array}$ & Iin $(\mathrm{A})$ & Vo (V) & Io (A) & $\begin{array}{c}\text { Pin } \\
\text { (Watt) }\end{array}$ & $\begin{array}{c}\text { Po } \\
\text { (Watt) }\end{array}$ \\
\hline 1 & $10 \%$ & \multirow{7}{*}{7,5} & \multirow{7}{*}{31} & 0.02 & 1.1 & 0.15 & 0.62 & 0.16 \\
\hline 2 & $20 \%$ & & & 0.04 & 2.2 & 0.28 & 1.24 & 0.62 \\
\hline 3 & $30 \%$ & & & 0.07 & 3.3 & 0.42 & 2.17 & 1.38 \\
\hline 4 & $40 \%$ & & & 0.14 & 5 & 0.65 & 4.34 & 3.25 \\
\hline 5 & $50 \%$ & & & 0.34 & 8.1 & 1 & 10.54 & 8.1 \\
\hline 6 & $60 \%$ & & & 0.65 & 11 & 1.6 & 20.15 & 15.73 \\
\hline 7 & $70 \%$ & & & 1.6 & 17.8 & 2.2 & 49.6 & 39.16 \\
\hline
\end{tabular}

\section{2 . Hasil gelombang output PWM}

Sebelum melakukan pengujian terlebih dahulu mensetting output flyback pada frekuensi yang telah ditentukan yaitu

dengan frekuensi $31 \mathrm{Khz}$.

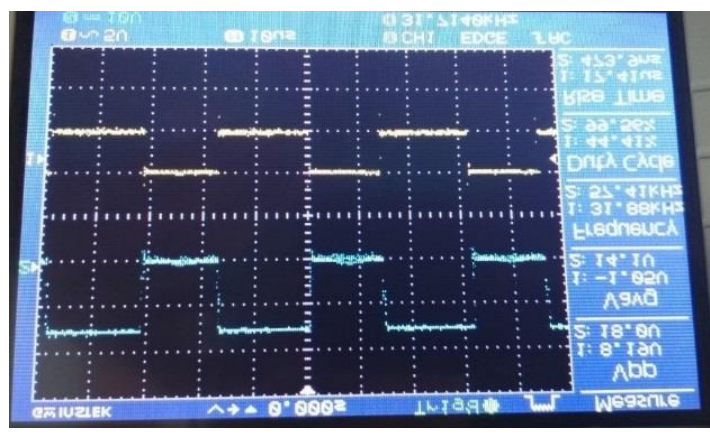

Gambar 11. Gelombang PWM dengan frekuensi $31 \mathrm{Khz}$

\subsection{Pengujian Flyback Converter}

\begin{tabular}{|c|c|c|c|c|c|c|c|}
\hline \multirow{2}{*}{ No. } & \multirow{2}{*}{$\begin{array}{c}\text { Beban } \\
(\Omega)\end{array}$} & \multicolumn{4}{|c|}{ Hasil pengujian } & \multicolumn{2}{|c|}{ Hasil perhitungan } \\
\hline & & $\begin{array}{l}\text { Vin } \\
\text { (V) }\end{array}$ & $\operatorname{Iin}(\mathrm{A})$ & $\begin{array}{l}\text { Vo } \\
\text { (V) }\end{array}$ & $\begin{array}{c}\text { Io } \\
\text { (A) }\end{array}$ & $\begin{array}{c}\text { Pin } \\
\text { (Watt) }\end{array}$ & Po (Watt) \\
\hline 1 & 38.16 & \multirow{7}{*}{31} & 0.22 & \multirow{7}{*}{15} & 0.4 & 6.82 & 6 \\
\hline 2 & 33.65 & & 0.26 & & 0.46 & 8.06 & 6.9 \\
\hline 3 & 27.94 & & 0.37 & & 0.54 & 11.47 & 8.1 \\
\hline 4 & 21.99 & & 0.39 & & 0.69 & 12.09 & 10.35 \\
\hline 5 & 15.40 & & 0.7 & & 1 & 21.7 & 15 \\
\hline 6 & 9.64 & & 0.98 & & 1.6 & 30.38 & 24 \\
\hline 7 & 3.96 & & 1.3 & & 2.2 & 40.3 & 33 \\
\hline
\end{tabular}

3.3.1. Pengujian flyback converter dengan tegangan keluaran konstan.

Tabel 1. Hasil Pengujian tegangan keluaran konstan flyback 


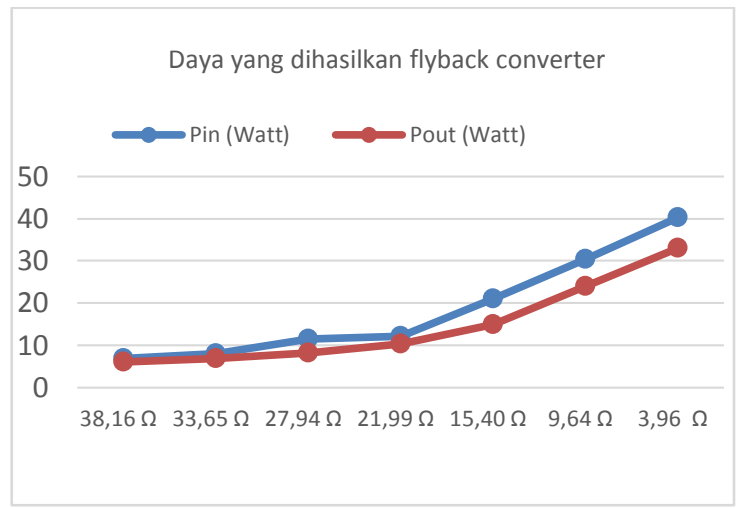

Gambar 12. Grafik antara daya input dan output terhadap beban

3.3.2. Pengujian flyback converter terhadap duty cycle dengan beban konstan

Tabel 2. Hasil Pengujian tegangan keluaran konstan flyback

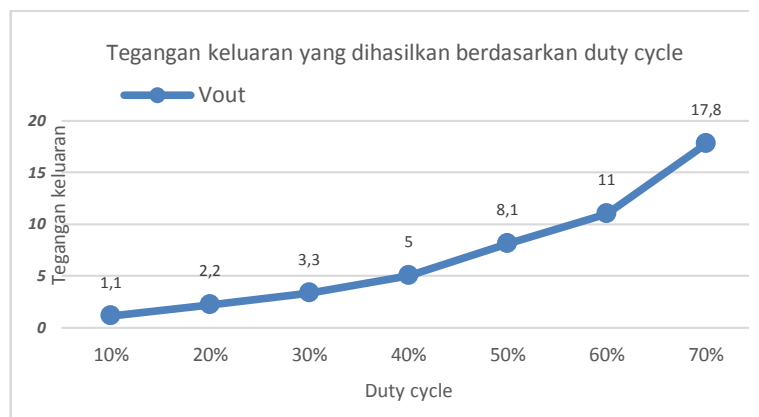

Gambar 13. Grafik tegangan keluaran terhadap Duty cycle

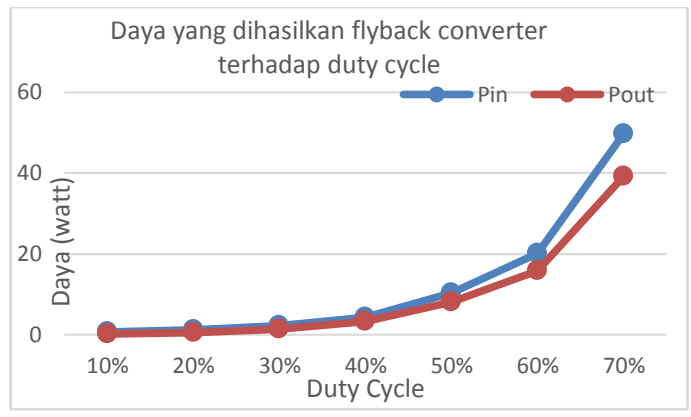

Gambar 14. Grafik antara daya input dan daya output terhadap Duty Cycle
3.3.3. Pengujian flyback converter terhadap beban dengan duty cycle konstan

\begin{tabular}{|c|c|c|c|c|c|c|c|c|}
\hline \multirow[t]{2}{*}{ No. } & \multirow{2}{*}{$\begin{array}{c}\text { Beban } \\
(\Omega)\end{array}$} & \multirow{2}{*}{$\begin{array}{l}\text { Duty } \\
\text { Cycle }\end{array}$} & \multicolumn{4}{|c|}{ Hasil pensujian } & \multicolumn{2}{|c|}{$\begin{array}{c}\text { Hasil } \\
\text { perhitungan }\end{array}$} \\
\hline & & & $\begin{array}{l}\text { Vin } \\
\text { (V) }\end{array}$ & $\begin{array}{l}\text { Iin } \\
\text { (A) }\end{array}$ & $\begin{array}{l}\text { Vo } \\
\text { (v) }\end{array}$ & $\begin{array}{l}\text { Io } \\
\text { (A) }\end{array}$ & $\begin{array}{c}\text { Pin } \\
\text { (watt) }\end{array}$ & $\begin{array}{c}P_{0} \\
\text { (watt) }\end{array}$ \\
\hline 1 & 38.16 & \multirow{7}{*}{$67 \%$} & \multirow{7}{*}{31} & 0.23 & 15 & 0.4 & 7.13 & 6 \\
\hline 2 & 33.65 & & & 0.25 & 15 & 0.44 & 7.75 & 6.6 \\
\hline 3 & 27.94 & & & 0.23 & 13.3 & 0.47 & 7.13 & 6.25 \\
\hline 4 & 21.99 & & & 0.22 & 11.3 & 0.51 & 6.82 & 5.76 \\
\hline 5 & 15.40 & & & 0.29 & 10.9 & 0.7 & 8,99 & 7.63 \\
\hline 6 & 9.64 & & & 0.68 & 10.5 & 1.1 & 21.08 & 11.55 \\
\hline 7 & 3.96 & & & 0.9 & 2.3 & 6.6 & 27,9 & 15.18 \\
\hline
\end{tabular}

Tabel 3. Pengujian flyback terhadap beban dengan duty cycle konstan

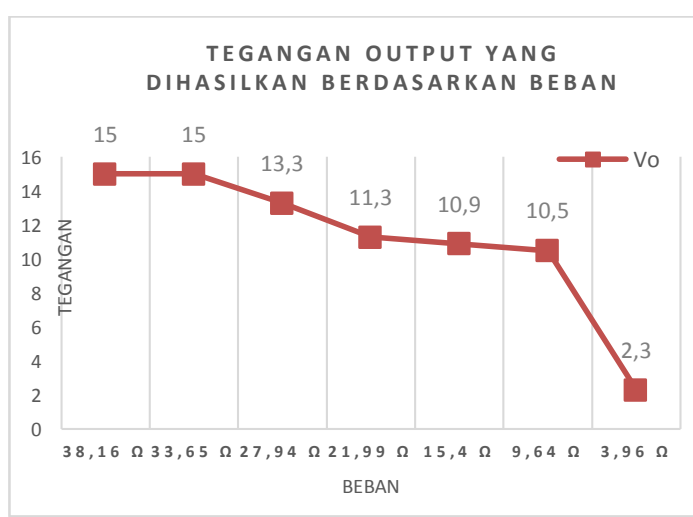

Gambar 15. Grafik tegangan keluaran flyback terhadap beban

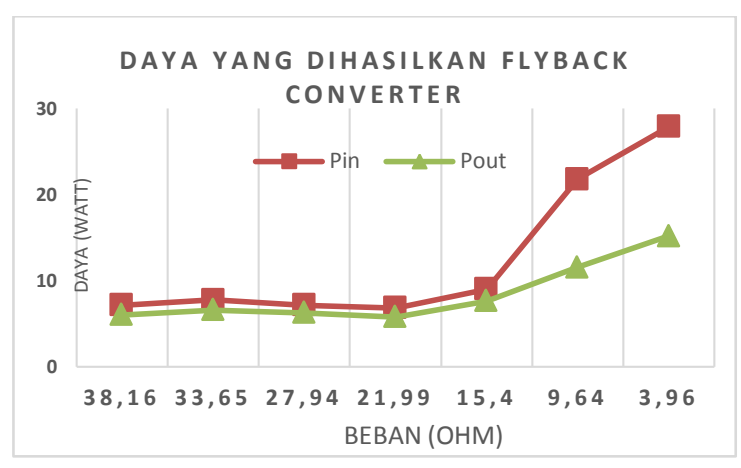

Gambar 16. Grafik antara daya input dan daya output terhadap beban 


\section{Penutup}

\subsection{Kesimpulan}

Pada pengujian flyback dengan tegangan output konstan dan dibebani resistor geser sudah bekerja dengan baik karena bisa menghasilkan tegangan keluaran $12 \mathrm{~V}$. Dengan kapasistas beban sebesar 39 Ohm. Sedangkan pada pengujian flyback terhadap duty cycle dengan beban konstan hanya dilakukan sampai duty $70 \%$ dikarenakan arus yang dihasilkan sudah melewati 2 Ampere dan efisiensi tidak cukup baik karena konstruksi trafo tidak bagus, jadi ketika beban tinggi, trafo panas.

\subsection{Saran}

Pada flyback converter ini menggunakan mosfet IRFP 460. Untuk hasil yang maksimal diharapkan menggunakan komponen yang memiliki rating arus dan tegangan lebih besar. Penggulungan trafo harus dilakukan dengan sebaik mungkin agar lonjakan tegangan dan arus yang sangat tinggi bisa hindari. Peredaman lonjakan tegangan pada mosfet dapat dilakukan dengan konfigurasi rangkaian snubber dan perhitungan yang tepat..

\section{Daftar Pustaka}

[1] Nurendi, D.M. et al. 2015. Perancangan dan Realisasi Pembangkit Korona dengan Sumber DC dari Baterai 12 Volt DC Menggunakan Flyback Converter, Jurnal Online, Institut Teknologi Nasional. Bandung

[2] Arduino ku . Arduino nano, tersedia dari:

https://djukarna4arduino.wordpress.c om/2018/3/30/arduino-nano/,(diakses tanggal 30 April 2018).

[3] Hamonangan, A. 2013 Dasar elektronika, Erlangga, Jakarta.

[4] Pambudi, g. Et al. 2009. Transformator design of flyback converter. Institut Teknologi Sepuluh Nopember, Surabaya

[5] Dharmawan, A. 2012. Pengendalian Motor Brushless DC dengan metode
PWM sinusoidal menggunakan Atmega16, Skripsi. Universitas Indonesia, Jakarta. 
